Indonesian Journal of Physical Education

e-ISSN 2745-942X

Journal Homepage: https://journal.uir.ac.id/index.php/SPORTIVO

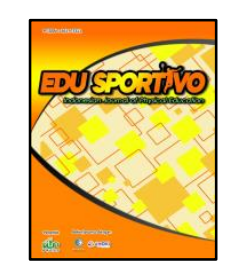

\title{
Model Kooperatif Teams Games Tournaments: Apakah dapat meningkatkan keterampilan belajar dribbling sepakbola?
}

\section{Teams Games Tournaments Cooperative Model: Can it improve soccer dribbling learning skills?}

\author{
${ }^{* 1}$ Lutfi Wildani, ${ }^{2}$ Novri Gazali \\ ${ }^{*} 1,2$ Pendidikan Jasmani Kesehatan dan Rekreasi, Universitas Islam Riau, Pekanbaru, Indonesia
}

Received: 24 September 2020; Accepted 05 December 2020; Published 09 December 2020

OPENOACCESS

\begin{tabular}{|c|c|}
\hline ABSTRAK & ABSTRACT \\
\hline $\begin{array}{l}\text { Penelitian ini bertujuan untuk meningkatkan keterampilan } \\
\text { belajar dribbling sepakbola pada siswa kelas XI IPA } 3 \text { SMA } \\
\text { Negeri } 12 \text { Pekanbaru dengan menggunakan model } \\
\text { kooperatif tipe TGT (Teams Games Tournaments). Jenis } \\
\text { penelitian ini menggunakan Penelitian Tindakan Kelas. } \\
\text { Subjek penelitian ini yaitu berjumlah } 20 \text { orang yang terdiri } \\
\text { dari } 15 \text { orang siswa laki-laki dan } 5 \text { siswi perempuan. Hasil } \\
\text { penelitian menunjukkan bahwa pada siklus I terdapat } 7 \\
\text { orang siswa yang tuntas dengan persentase } 35 \% \text { dan siswa } \\
\text { yang tidak tuntas sebanyak } 13 \text { orang siswa dengan } \\
\text { persentase } 65 \% \text {, sedangkan pada siklus II terdapat } 16 \text { orang } \\
\text { siswa yang tuntas dengan persentase } 80 \% \text { dan siswa yang } \\
\text { tidak tuntas sebanyak } 4 \text { orang dengan persentase } 20 \% \text {. } \\
\text { Berdasarkan hasil penelitian yang dilakukan melalui proses } \\
2 \text { siklus, maka diperoleh kesimpulan yaitu model kooperatif } \\
\text { tipe TGT (Teams Games Tournaments) dapat meningkatkan } \\
\text { keterampilan dribbling sepakbola siswa kelas XI IPA } 3 \text { SMA } \\
\text { Negeri } 12 \text { Pekanbaru. Diharapkan model kooperatif tipe } \\
\text { TGT (Teams Games Tournaments) ini bisa juga diterapkan } \\
\text { pada semua cabang olahraga yang dipelajari di sekolah. }\end{array}$ & $\begin{array}{l}\text { This study aims to improve learning skills for soccer dribbling } \\
\text { in class XI IPA } 3 \text { SMA Negeri } 12 \text { Pekanbaru by using the TGT } \\
\text { (Teams Games Tournaments) type cooperative model. This } \\
\text { type of research uses Classroom Action Research. The } \\
\text { subjects of this study were } 20 \text { people consisting of } 15 \text { male } \\
\text { students and } 5 \text { female students. The results showed that in } \\
\text { cycle I there were } 7 \text { students who completed with a } \\
\text { percentage of } 35 \% \text { and students who did not complete were } \\
13 \text { students with a percentage of } 65 \% \text {, while in cycle II there } \\
\text { were } 16 \text { students who completed with a percentage of } 80 \% \\
\text { and students who did not complete as many as } 4 \text { people with } \\
\text { a percentage of } 20 \% \text {. Based on the results of research } \\
\text { conducted through a } 2 \text {-cycle process, it is concluded that the } \\
\text { cooperative model type TGT (Teams Games Tournaments) } \\
\text { can improve the football dribbling skills of class XI IPA } 3 \\
\text { students of SMA Negeri } 12 \text { Pekanbaru. It is hoped that the } \\
\text { TGT (Teams Games Tournaments) type of cooperative model } \\
\text { can also be applied to all sports that are studied in schools. }\end{array}$ \\
\hline $\begin{array}{l}\text { Kata Kunci: Kooperatif; Teams Games Tournaments; } \\
\text { Dribbling; Sepakbola }\end{array}$ & $\begin{array}{l}\text { Keywords: Cooperative; Teams Games Tournaments; } \\
\text { Dribbling; Football }\end{array}$ \\
\hline $\begin{array}{l}\text { *Corresponding Author } \\
\text { Email: lutfiwildani@student.uir.ac.id }\end{array}$ & doi https://doi.org/10.25299/es:ijope.2020.vol1(2).5637 \\
\hline
\end{tabular}

How To Cite: Wildani, L., \& Gazali, N. (2020). Model Kooperatif Teams Games Tournaments: Apakah dapat meningkatkan keterampilan belajar dribbling sepakbola? Edu Sportivo: Indonesian Journal of Physical Education, 1(2), 103-111. https://doi.org/10.25299/es:ijope.2020.vol1(2).5637

\section{PENDAHULUAN}

Pendidikan adalah suatu usaha untuk mewujudkan aktivitas belajar dan mengembangkan setiap potensi yang ada dari peserta didik agar memiliki keterampilan untuk dirinya maupun untuk masyarakat. Pendidikan bersifat universal, bisa terbagi ke dalam beberapa aspek, salah satunya adalah pendidikan jasmani (Burstiando \& Nurkholis, 2017). Pendidikan merupakan suatu proses pembinaan manusia yang berlangsung selama seumur hidup (Taufik, 2019). Pendidikan berintikan interaksi antara pendidik dengan peserta didik dalam upaya membantu peserta didik menguasai tujuan- 
tujuan pendidikan. Interaksi pendidikan dapat berlangsung dalam lingkungan keluarga, sekolah, ataupun masyarakat (Nurfajrin, 2014). Pendidikan jasmani bukan hanya untuk meningkatkan kebugaran jasmani akan tetapi juga memberikan gerak bervariasi dan bermakna bagi anak (Faud, 2014).

Sepakbola merupakan salah satu cabang olahraga permainan beregu, satu regu terdiri dari 11 orang pemain dan termasuk satu orang penjaga gawang (Nirwandi, 2017). Sepakbola sangat digemari oleh semua kalangan, baik anak-anak sampai dewasa (Pratama, 2019), bahkan di dalam pembelajaran formalpun olahraga ini menjadi salah satu materi pembelajaran pada mata pelajaran pendidikan jasmani (Kuswoyo, Wasa, \& Donggoran, 2020). Sepakbola dikenal dengan permainan tim, walaupun terkadang pada situasi tertentu para permainan mempunyai keterampilan yang baik bisa menguasai, tetap pemain juga harus saling bekerja sama kepada sesama anggota tim agar menghasilkan permainan yang baik dan menciptakan suatu keputusan yang terbaik. Tentu semua tidak lepas dari kemampuan teknik dasar yang harus dimiliki oleh setiap pemain seperti keterampilan mengumpan bola, menerima bola, dan menggiring bola. Pemain sepakbola harus memiliki kemampuan teknik, taktik dan keterampilan fisik yang baik untuk dapat mencapai prestasi optimal (Rusmanto, Lardika, \& Muspita, 2020). Teknik dasar tersebut antara lain; stopping (menghentikan bola), shooting (menendang bola ke gawang), passing (mengumpan), dribbling (menggiring bola), dan heading (menyundul bola) (Kuswoyo et al., 2020). Teknik dasar yang dibahas dalam penelitian ini yaitu dribbling.

Dribbling atau menggiring bola adalah keterampilan dasar dalam sepakbola karena semua pemain harus menguasai bola saat sedang bergerak, berdiri, atau bersiap melakukan operan atau tembakan (Mielke, 2007). Sepintas terlihat bermain sepakbola mudah dan sederhana, bahkan hampir semua orang mengaku sanggup bermain sepakbola, namun kenyataanya tidaklah semudah seperti yang dibayangkan, karena dalam melakukan permainan sepakbola tidak boleh pasif berdiri saja harus bergerak, idealnya seorang pemain sepakbola harus memiliki kondisi fisik yang baik, keterampilan teknik yang baik dan kesiapan mental yang mantap (Prasetyo, 2019). Banyak orang melakukan olahraga sepakbola dengan berbagai macam tujuan, di antaranya untuk rekreasi dan hiburan, menjaga kebugaran dan kesehatan sampai untuk tujuan olahraga prestasi (Yulianto, 2016).

Teknik dasar dribbling penting dalam pemainan sepakbola. Dribbling yakni suatu upaya membawa bola melalui kaki, baik dengan menggunakan satu kaki maupun kedua kaki secara bergantian dengan keadaan bola tetap berada dalam jangkauan kita. Menggiring bola selain untuk mengatur tempo, menyusun serangan serta transisi,juga berguna untuk mencetak gol ke gawang lawan dengan cara melewati penjaga gawang jika sudah berhadapan langsung dengan penjaga gawang tersebut (Marta \& Oktarifaldi, 2020). Dribbling sepakbola bisa dilakukan dengan bagian punggung kaki sebelah dalam, dribbling dengan punggung kaki dan dribbling dengan bagian punggung kaki bagian dalam (Aprianova, 2016). Namun banyak di antara siswa masih kurang dalam melakukan dribbling sepakbola, maka peneliti mencoba memberikan model pembelajaran kooperatif tipe TGT (Teams Games Tournament) Model pembelajaran kooperatif tipe TGT (Teams Games Tournament) adalah suatu model pembelajaran kooperatif yang mudah diterapkan, yakni dengan menyertakan aktivitas seluruh siswa tanpa ada perbedaan status yang mana pada model pembelajaran ini terdapat unsur permainan. TGT adalah salah satu tipe pembelajaran kooperatif yang menempatkan siswa dalam kelompokkelompok belajar yang beranggotakan 5 sampai 6 orang siswa yang memiliki kemampuan, jenis kelamin dan suku kata atau ras yang berbeda (Rusman, 2018). 
Pembelajaran kooperatif Team Games Tournament (TGT) ini memiliki kelebihan dan kekurangan, yaitu: Kelebihan dari model pembelajaran TGT yaitu: (1) lebih mengoptimalkan pencurahan waktu untuk tugas gerak, (2) mengedepankan penerimaan terhadap perbedaan individu, (3) dengan waktu yang sedikit dapat menguasai materi lebih mendalam, (4) kegiatan belajar mengajar berlangsung dengan keaktifan dari siswa. (5) mendidik siswa untuk berlatih bersosialisasi dengan orang lain, (6) semangat belajar lebih tinggi, (7) hasil belajar lebih baik, (8) meningkatkan kebaikan budi, kerjasama, dan persaingan sehat. Kekurangan dari model pembelajaran TGT yaitu: (1) sulitnya pengelompokan siswa yang memiliki kemampuan heterogen dari segi akademis, (2) masih adanya siswa berkemampuan tinggi tidak terbiasa dan susah memberikan penjelasan kepada siswa lainnya (Riski, 2013). Gazali (2016) juga menyampaikan bahwa keunggulan model kooperatif ini dalam pembelajaran keterampilan teknik dasar bermain sepakbola adalah: (1) siswa lebih leluasa mengembangkan keterampilan teknik dasar bermain sepakbola berdasarkan potensi yang dimilikinya, (2) siswa dapat belajar keterampilan teknik dasar bermain sepakbola dari teman sekelompok, (3) pemanfaatan waktu belajar keterampilan teknik dasar bermain sepakbola lebih efektif dalam penggunaan waktu pelajaran, (4) siswa tidak terlalu lama menunggu giliran untuk melakukan latihan.

Berdasarkan observasi yang dilaksanakan pada siswa kelas XI IPA 3 SMA Negeri 12 Pekanbaru, terlihat teknik-teknik dasar dalam permainan sepakbola terutama dalam teknik dribbling, di antaranya siswa masih sering melakukan kesalahan-kesalahan seperti menggiring bola berada di luar penguasaan dan terlalu jauh dari kaki, bola tersemat di sela-sela kaki saat dribbling, masih adanya siswa yang belum serius dalam melakukan kegiatan olahraga sehingga tidak melakukan teknik dasar dribbling dengan baik dan masih adanya siswa yang mendapatkan nilai di bawah KKM yang telah ditetapkan oleh guru yaitu sebesar 75. Di sini penulis berpendapat bahwasannya pembelajaran model kooperatif tipe TGT (Teams Games Tournaments) dapat meningkatkan keterampilan dribbling sepakbola pada siswa. Tujuan dari penelitian ini yaitu untuk meningkatkan keterampilan belajar dribbling sepakbola pada siswa kelas XI IPA 3 SMA Negeri 12 Pekanbaru dengan menggunakan model kooperatif tipe TGT (Teams Games Tournaments).

\section{METODE PENELITIAN}

Jenis penelitian ini menggunakan penelitian tindakan kelas yaitu penelitian yang dilakukan dalam kelas dengan tujuan untuk meningkatkan kemampuan teknik dasar dribbling sepakbola melalui model kooperatif tipe TGT (Teams Games Tournaments). Menurut Arikunto (2015) bahwa Penelitian Tindakan Kelas (PTK) merupakan penelitian yang dilakukan oleh guru dengan tujuan untuk memperbaiki kualitas pembelajaran di kelasnya. Subjek penelitian ini adalah siswa kelas XI IPA 3 SMA Negeri 12 Pekanbaru yang berjumlah 20 orang siswa terdiri dari 15 siswa dan 5 siswi. Teknik pengumpulan data yang digunakan dalam Penelitian Tindakan Kelas (PTK) berpedoman pada observasi, kepustakaan, dan rubrik penilaian. Teknik analisi data yang digunakan dalam penelitian ini menggunakan rumus yang digunakan untuk ketuntasan klasikal. Rubrik unjuk kerja dalam penelitian ini dapat dilihat pada tabel 1. 
Tabel 1. Rubrik Unjuk Kerja Dribbling Sepakbola

\begin{tabular}{|c|c|c|c|c|c|c|}
\hline \multirow{2}{*}{ No } & \multirow{2}{*}{ Indikator } & \multirow{2}{*}{ Deskriptor } & \multicolumn{4}{|c|}{ Skor } \\
\hline & & & 4 & 3 & 2 & 1 \\
\hline \multirow{4}{*}{1} & \multirow{4}{*}{ Sikap Permulaan } & $\begin{array}{l}\text { 1. Diawali dengan sikap berdiri } \\
\text { menghadap arah gerakan dan pandangan } \\
\text { ke depan }\end{array}$ & & & & \\
\hline & & $\begin{array}{l}\text { 2. Sikap kedua lengan di samping badan } \\
\text { agak terlentang }\end{array}$ & & & & \\
\hline & & $\begin{array}{l}\text { 3. Posisi kaki saat dribbling bola } \\
\text { menggunakan kaki bagian dalam }\end{array}$ & & & & \\
\hline & & 4. Kaki diputar keluar & & & & \\
\hline \multirow{3}{*}{2} & \multirow{3}{*}{ Sikap Perkenaan } & $\begin{array}{l}\text { 1. Dorong bola dengan kaki bagian dalam } \\
\text { ke arah depan dalam posisi agak } \\
\text { terangkat dari tanah }\end{array}$ & & & & \\
\hline & & $\begin{array}{l}\text { 2. Berat badan ditumpukan di kaki yang } \\
\text { tidak digunakan untuk menggiring bola }\end{array}$ & & & & \\
\hline & & $\begin{array}{l}\text { 3. Bola bergerak ke depan di permukaan } \\
\text { tanah tidak jauh dari kaki }\end{array}$ & & & & \\
\hline 3 & Sikap Akhir & $\begin{array}{l}\text { 1. Dribbling yang dilakukan harus } \\
\text { melewati lintasan yang sudah ditentukan } \\
\text { dengan menggunakan cone }\end{array}$ & & & & \\
\hline
\end{tabular}

\section{Keterangan:}

1. Jika siswa melakukan butir indikator dengan sangat baik atau melakukan semua gerakan dengan benar maka akan diberi poin 4 .

2. Jika siswa melakukan butir indikator dengan baik atau hanya melakukan kesalahan pada satu gerakan indikator maka akan diberi poin 3 .

3. Jika siswa melakukan butir indikator dengan cukup baik atau hanya melakukan kesalahan pada dua gerakan indikator maka diberi poin 2 .

4. Jika siswa melakukan butir indikator dengan kurang baik atau melakukan kesalahan lebih dari 2 indikator makan diberi poin 1.

Dalam mengukur ketuntasan siswa peneliti memakai pedoman penilaian dari pusat penilaian (Depdiknas, 2007), yaitu sebagai berikut:

Nilai Tes Unjuk Kerja: $\quad: \quad \frac{\text { Jumlah Skor Yang Diproleh }}{\text { Jumlah }} \times 100$

\section{HASIL PENELITIAN}

Hasil penelitian ini memaparkan data kemampuan persentase klasikal anak menguasai teknik dasar dribbling sepakbola menggunakan model kooperatif tipe TGT (Teams Games Tournament) siswa kelas XI IPA 3 SMA Negeri 12 Pekanbaru pada siklus 1 dan 2.

Tabel 2. Distribusi Frekuensi Data Siklus I Dribbling Sepakbola

\begin{tabular}{cccc}
\hline No & Interval & Frekuensi & Persentase \\
\hline 1 & $50-57$ & 4 & $20 \%$ \\
2 & $58-65$ & 7 & $35 \%$ \\
3 & $66-73$ & 2 & $10 \%$ \\
4 & $74-81$ & 4 & $20 \%$ \\
5 & $82-89$ & 2 & $10 \%$ \\
6 & $90-97$ & 1 & $5 \%$ \\
\hline & Jumlah & $\mathbf{2 0}$ & $\mathbf{1 0 0 \%}$ \\
\hline
\end{tabular}


Bersumber pada tabel di atas, didapat data dengan interval penelitian siswa, yakni 4 siswa (20\%) dengan interval 50-57, 7 siswa (35\%) dengan interval 58-65, 2 siswa (10\%) dengan interval 66-73, 4 siswa (20\%) dengan interval 74-81, 2 siswa (10\%) dengan interval 82-89, 1 siswa (5\%) dengan interval 90-97. Pada hasil penelitian siklus I diperoleh jumlah rata-rata persentase kemampuan dribbling sepakbola siswa adalah $35 \%$ dengan siswa yang tuntas 7 orang dan yang tidak tuntas sebanyak 13 orang. Agar lebih jelas dapat dilihat pada grafik 1.

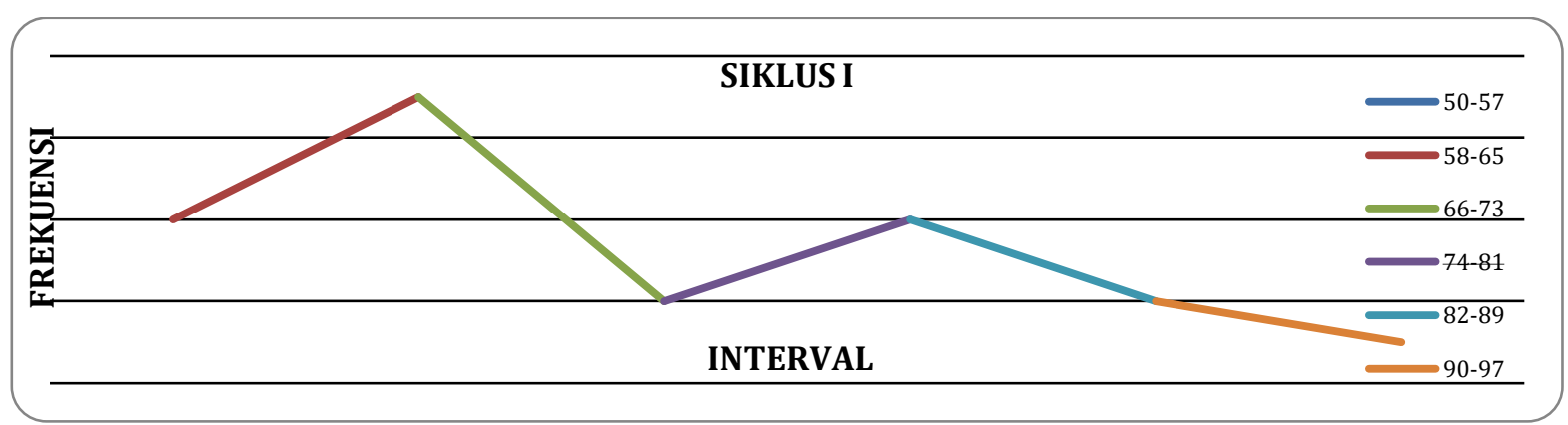

Grafik 1. Hasil Pembelajaran Dribbling Sepakbola Siklus I Kelas XI IPA 3

Tabel 3. Distribusi Frekuensi Data Siklus II Dribbling Sepakbola

\begin{tabular}{cccc}
\hline No & Interval & Frekuensi & Persentase \\
\hline 1 & $50-57$ & 0 & $0 \%$ \\
2 & $58-65$ & 0 & $0 \%$ \\
3 & $66-73$ & 4 & $20 \%$ \\
4 & $74-81$ & 8 & $40 \%$ \\
5 & $82-89$ & 5 & $25 \%$ \\
6 & $90-97$ & 3 & $15 \%$ \\
\hline & Jumlah & $\mathbf{2 0}$ & $\mathbf{1 0 0 \%}$ \\
\hline
\end{tabular}

Berdasarkan tabel di atas, didapat data dengan interval penelitian siswa, yakni 0 siswa (0\%) dengan interval 50-57, 0 siswa (0\%) dengan interval 58-65, 4 siswa (20\%) dengan interval 66-73, 8 siswa (40\%) dengan interval 74-81, 5 siswa (25\%) dengan interval 8289, 3 siswa (15\%) dengan interval 90-97. Hasil penelitian siklus II diperoleh jumlah ratarata persentase kemampuan dribbling sepakbola siswa adalah 80\%. Dari hasil penelitian pada siklus II terjadi peningkatan jumlah rata-rata persentase kemampuan dribbling sepakbola dengan siswa yang tuntas 16 orang dan yang tidak tuntas sebanyak 4 orang. Agar mudah dipahami dapat dilihat pada grafik 2.

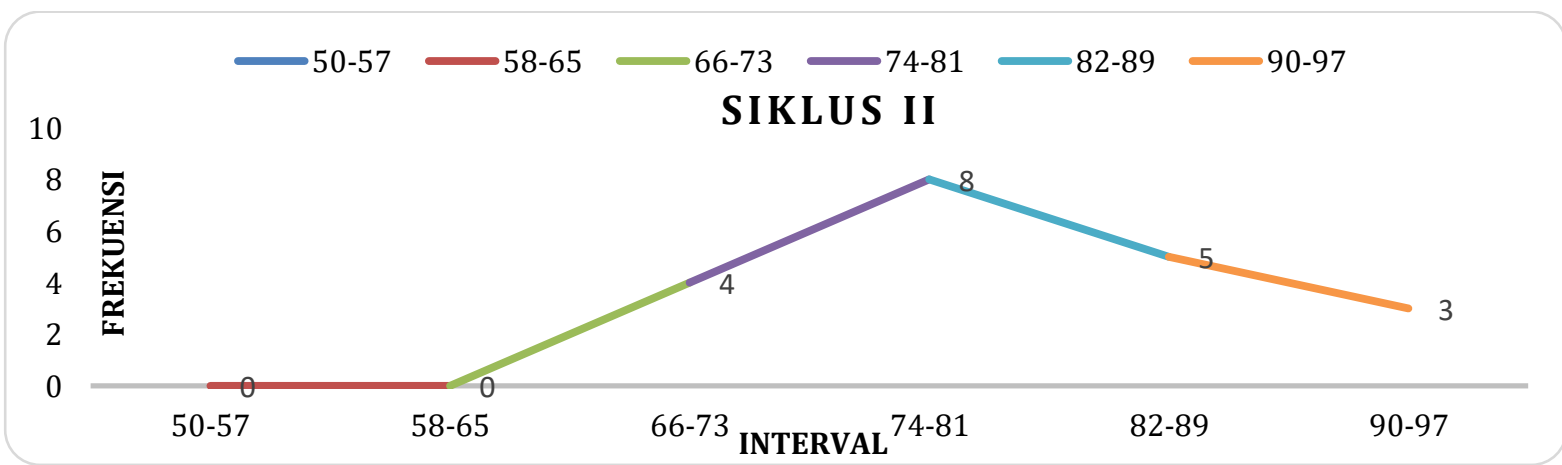

Grafik 2. Hasil Pembelajaran Dribbling Sepakbola Siklus I Kelas XI IPA 3 
Edu Sportivo: Indonesian Journal of Physical Education

Lutfi Wildani dan Novri Gazali, 1(2), 103-111

[2020]

Tabel 4. Perbandingan Hasil Penilaian Kemampuan Dribbling Sepakbola

\begin{tabular}{cccc} 
Kategori & Siklus I & Siklus II & Keterangan \\
\cline { 1 - 3 } Tuntas & 7 siswa $(35 \%)$ & 16 siswa $(80 \%)$ & Adanya \\
\cline { 1 - 3 } peningkatan \\
\cline { 1 - 3 } Jidak Tintas & 13 siswa $(65 \%)$ & siswa $(20 \%)$ & sebesar $45 \%$ \\
\hline
\end{tabular}

Perbandingan

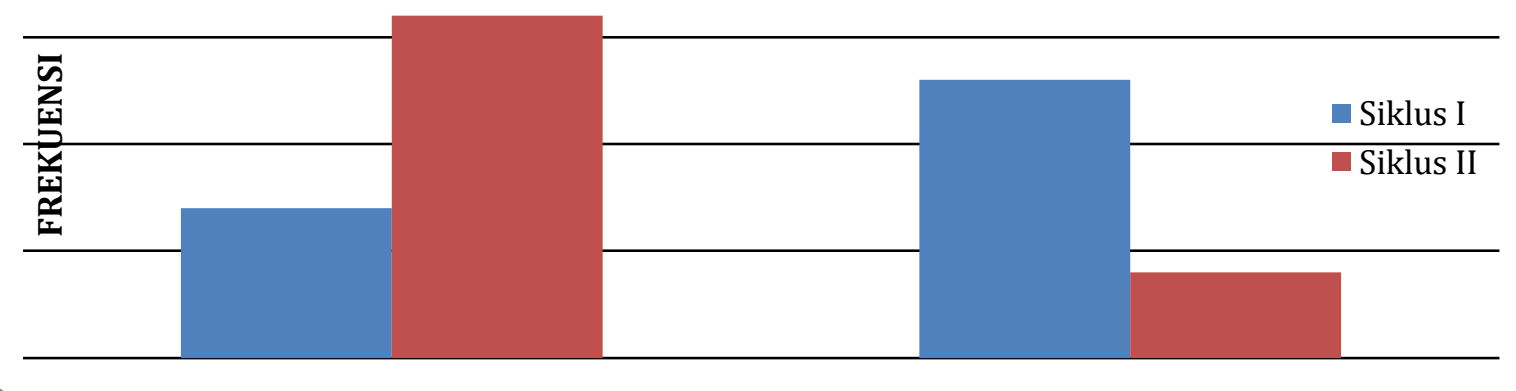

Grafik 3. Perbandingan Hasil Pembelajaran Siklus I dan Siklus II Keterampilan Dribbling Sepakbola

\section{PEMBAHASAN}

Penerapan model kooperatif tipe TGT (Teams Games Tournament) terhadap keterampilan dribbling sepakbola pada siswa kelas XI IPA 3 SMA Negeri 12 Pekanbaru menunjukkan adanya sebuah peningkatan. Dilihat dari hasil penelitian yang menunjukkan nilai persentase rata-rata siklus I sebesar 35\% yang kemudian meningkat pada siklus II dengan persentase rata-rata sebesar $80 \%$ dan total jumlah kenaikan persentase rata-rata sebesar 45\%. Berdasarkan hasil penelitian Kariyana (2013) terbukti bahwa aktivitas belajar dribbling sepakbola meningkat melalui implementasi model pembelajaran kooperatif tipe TGT. Sama halnya dengan penelitian Karina, Yudha (2019) mengatakan pengaruh model pembelajaran kooperatif tipe TGT terhadap hasil belajar dribbling sepakbola sebab ini dapat dibuktikan pada perhitungan persentase pengaruh sebesar 24\% untuk pengetahuan dan $26 \%$ untuk keterampilan. Dari temuan ini, penulis semakin yakin bahwasannya pembelajaran kooperatif dengan menggunakan tipe TGT (Teams Games Tournaments) dapat meningkatkan keterampilan dribbling sepakbola pada siswa.

Berdasarkan uraian yang dijelaskan sebelumnya, pada siklus I banyaknya siswa tidak tuntas hal ini dikarenakan siswa masih takut atau enggan melakukan gerakan dribbling sepakbola dan terlalu tergesa-gesa pada saat menggiring bola, bola yang terlalu jauh dari jangkauan kaki, bola yang digiring tidak melewati lintasan cone. Oleh karena itu penguasaan teknik dasar sangat penting dalam permainan sepakbola. Jumlah siswa yang tidak tuntas pada siklus II sebanyak 4 orang dari jumlah objek penelitian 20 orang. Dibandingkan dengan jumlah siswa yang tidak tuntas pada siklus I yaitu sebanyak 13 orang, maka pada siklus II jumlah siswa tidak tuntas sudah mengalami penurunan. Hal ini dikarenakan dari konsep pembelajaran kooperatif tipe TGT (Teams Games Tournament) dengan memberikan siswa pertandingan permainan secara tim dan memberikan sebuah hadiah untuk tim yang menang dalam pertandingan tersebut membuat siswa lebih antusias dan semangat dalam melakukan pembelajaran khususnya pembelajaran dribbling sepakbola ini.

Seperti yang disebutkan oleh Danang (2017) keberhasilan penerapan kooperatif tidak terlepas dari keberhasilan guru dalam menerapkan empat prinsip model pembelajaran 
kooperatif, yaitu: (1) akuntabilitas, (2) penghargaan, (3) keterkaitan individu dengan yang lain, (4) heterogenitas grup. Pelaksanaan model pembelajaran kooperatif tidak terlepas dari kelompok-kelompok siswa yang belajar bersama. Hal tersebut membuktikan bahwasannya pembelajaran sepakbola dengan menggunakan model kooperatif tipe TGT dapat meningkatkan keterampilan dribbling sepakbola siswa pada kelas XI IPA 3 SMA Negeri 12 Pekanbaru.

\section{KESIMPULAN}

Berdasarkan hasil penelitian yang telah dilakukan melalui proses pembelajaran selama 2 siklus terhadap keterampilan dribbling sepakbola pada siswa kelas XI IPA 3 SMA Negeri 12 Pekanbaru dengan menggunakan model pembelajaran kooperatif tipe TGT (Teams Games Tournaments) dapat diperoleh kesimpulan yaitu terjadinya sebuah peningkatan keterampilan dribbling sepakbola pada siswa. Pada siklus I terdapat 7 siswa yang tuntas dengan persentase 35\% sedangkan pada siklus II terdapat 16 siswa yang tuntas dengan persentase $80 \%$. Jadi, hasil penelitian keterampilan dribbling sepakbola pada siswa kelas XI IPA 3 SMA Negeri 12 Pekanbaru dengan menggunakan model kooperatif tipe TGT (Teams Games Tournaments) mengalami peningkatan sebesar 45\%. Berdasakan temuan penelitian, diharapkan guru pendidikan jasmani bisa menjadikan model kooperatif tipe TGT (Teams Games Tournaments) salah satu solusi dalam meningkatkan kemampuan teknik dasar olahraga siswa, khususnya cabang sepakbola.

\section{DAFTAR PUSTAKA}

Aprianova, F., \& Hariadi, I. (2017). Metode Drill Untuk Meningkatkan Teknik Dasar Menggiring Bola (Dribbling) Dalam Permainan Sepakbola Pada Siswa Sekolah Sepakbola Putra Zodiac Kabupaten Bojonegoro Usia 13-15 Tahun. Indonesia Performance Journal, 1(1), 63-74.

Arikunto, S. (2015). Penelitian Tindakan Kelas. Depok: PT Rajagrafindo Persada.

Burstiando, R., \& Nurkholis, M. (2017). Permainan Invasi dan Permainan Netting untuk Meningkatkan Keterampilan Gerak Dasar Fundamental Siswa SD Negeri Se Kecamatan Mojoroto Kota Kediri. Sportif : Jurnal Penelitian Dan Pembelajaran, 3(2), 167-177. https://doi.org/10.29407/js_unpgri.v3i2.11892

Danang, S. R. (2017). Penerapan Model Pembelajaran Kooperatif Tipe Teams Games Tournament (TGT) Terhadap Hasil Belajar Dribbling Sepakbola. Jurnal Pendidikan Olahraga dan Kesehatan, 5(3), 5-14.

Depdiknas. (2007). Kurikulum Tingkat Satuan Pendidikan (KTSP). Jakarta: Depdiknas.

Fuad, M. (2014). Pengaruh Metode Pembelajaran Tutor Sebaya Terhadap Hasil Belajar Dribble Sepakbola (Studi Pada Siswa Kelas VIII SMP Negeri 1 Genteng Banyuwangi). Jurnal Pendidikan Olahraga dan Kesehatan, 2(2), 1-8.

Gazali, N. (2016). Pengaruh Metode Kooperatif dan Komando Terhadap Keterampilan Teknik Dasar Bermain Sepakbola.Journal Sport Area,1(1), 56-62. https://doi.org/10.25299/sportarea.2016.vol1(1).373 
Kariyana, I. K. (2013). Implementasi Pembelajaran Koopeatif TGT Untuk Meningkatkan Aktivitas dan Hasil Belajar Dribbling Sepakbola. Jurnal Pendidikan Jasmani, Olahraga Dan Kesehatan Undiksha, 1(5), 1-10.

Kuswoyo, D. D., Wasa, C., \& Donggoran, M. F. (2020). Pengaruh latihan back-up terhadap kemampuan menyundul bola. Edu Sportivo: Indonesian Journal of Physical Education, 1(1), 33-41. https://doi.org/10.25299/es:ijope.2020.vol1(1).5190.

Marta, I. A., \& Oktarifaldi, O. (2020). Koordinasi Mata-Kaki dan Kelincahan terhadap Kemampuan Dribbling Sepakbola. Gelanggang Olahraga: Jurnal Pendidikan Jasmani dan Olahraga. 4(1), 1-14. https://doi.org/10.31539/jpjo.v4i1.1201

Mielke, D. (2007). Dasar-Dasar Sepak Bola. Bandung: PT Intan Sejati.

Nirwandi, N. (2018). Tinjauan Tingkat V02 Max Pemain Sepakbola Sekolah Sepakbola Bima Junior Bukittinggi. Jurnal Penjakora, 4(2), 18-27. http://dx.doi.org/10.23887/penjakora.v4i2.13362

Nurfajrin, Y. (2014). Pengaruh Penerapan Model Pembelajaran Kooperatif Tipe Numbered Head Together (NHT) Terhadap Hasil Belajar Dribbling Sepakbola (Studi Pada Siswa Kelas XI SMA Negeri 1 Tarik Sidoarjo). Jurnal Pendidikan Olahraga dan Kesehatan, 2(2), 1-9.

Prasetyo, Y. T., \& Irianto, S. (2019). Pengaruh Metode Latihan Lari Percepatan dan Lari Interval Terhadap Peningkatan Dribbling Pada Pemain Sepakbola Ku 14 Tahun di SSB Pandawa. Pend. Kepelatihan Olahraga-S1, 8(8), 3-9.

Pratama, R. R. (2019). Pengaruh Gizi, Motivasi dan Percaya Diri Terhadap Prestasi Atlet Sepakbola Universitas Sriwijaya. Journal of Sport Education (JOPE), 1(2), 37-42.

Riski, N. D. (2013). Penerapan Model Pembelajaran Kooperatif Tipe (Times Games Tournaments) TGT Terhadap Motivasi Siswa Mengikuti Pembelajaran Bola Voli di Kelas X SMAN 1 Panggul Kabupaten Trenggalek. Jurnal Pendidikan Olahraga dan Kesehatan, 1(1), 161-165.

Rusman. (2018). Model-Model Pembelajaran Mengembangkan Profesionalisme Guru. Depok: PT Rajagrafindo Persada.

Rusmanto., Lardika, R. A., \& Muspita. (2020). Efektivitas metode resiprokal terhadap keterampilan dasar bermain sepakbola: Studi eksperimen. Edu Sportivo: Indonesian $\begin{array}{lllll}\text { Journal of Physical 1-8. } & \text { Education, }\end{array}$ https://doi.org/10.25299/es:ijope.2020.vol1(1).5165

Taufik, M. S. (2019). Peningkatan Hasil Belajar Dribbling Sepakbola Dengan Penggunaan Media Audio Visual. Jp.jok (Jurnal Pendidikan Jasmani, Olahraga dan Kesehatan), 3(1), 43-54. https://doi.org/10.33503/jp.jok.v3i1.540

Yudha, B. D. (2019). Pengaruh Model Pembelajaran Kooperatif Tipe Team Games Tournament (TGT) Terhadap Hasil Belajar Dribbling Sepak Bola. Jurnal Pendidikan Olahraga dan Kesehatan, 7(3), 10-19. 
Yulianto, P. F. (2016). Perbedaan Pengaruh Pendekatan Pembelajaran Metode Bagian dan Keseluruhan Terhadap Peningkatan Dribble Shooting Sepakbola Ditinjau Dari Koordinasi Mata-Kaki (Studi Eksperimen Pada Mahasiswa Pembinaan Prestasi Sepakbola Fakultas Keguruan dan Ilmu Pendidikan. Jurnal Ilmiah SPIRIT, 16(1), 1429. https://doi.org/10.36728/jis.v16i1.502 